\title{
Biodegradation of waste lubricants by a newly isolated Ochrobactrum sp. C1
}

\author{
Munna Bhattacharya $\cdot$ Dipa Biswas • \\ Santanu Sana $\cdot$ Sriparna Datta
}

Received: 27 April 2014/Accepted: 3 February 2015/Published online: 3 March 2015

(C) The Author(s) 2015. This article is published with open access at Springerlink.com

\begin{abstract}
A potential degrader of paraffinic and aromatic hydrocarbons was isolated from oil-contaminated soil from steel plant effluent area in Burnpur, India. The strain was investigated for degradation of waste lubricants (waste engine oil and waste transformer oil) that often contain EPA (Environmental Protection Agency, USA) classified priority pollutants and was identified as Ochrobactrum sp. $\mathrm{C} 1$ by $16 \mathrm{~S}$ rRNA gene sequencing. The strain $\mathrm{C} 1$ was found to tolerate unusually high waste lubricant concentration along with emulsification capability of the culture broth, and its degradation efficiency was $48.5 \pm 0.5 \%$ for waste engine oil and $30.47 \pm 0.25 \%$ for waste transformer oil during 7 days incubation period. In order to get optimal degradation efficiency, a three level Box-Behnken design was employed to optimize the physical parameters namely $\mathrm{pH}$, temperature and waste oil concentration. The results indicate that at temperature $36.4{ }^{\circ} \mathrm{C}, \mathrm{pH} 7.3$ and with $4.6 \%$ $(\mathrm{v} / \mathrm{v})$ oil concentration, the percentage degradation of waste engine oil will be $57 \%$ within 7 days. At this optimized condition, the experimental values $(56.7 \pm 0.25 \%)$ are in a good agreement with the predicted values with a calculated $R^{2}$ to be 0.998 and significant correlation between biodegradation and emulsification activity $\left(E_{24}=69.42 \pm\right.$ $0.32 \%$ ) of the culture broth toward engine oil was found with a correlation coefficient of 0.972 . This is the first study showing that an Ochrobactrum sp. strain is capable of degrading waste lubricants, which might contribute to the bioremediation of waste lubricating oil-contaminated soil.
\end{abstract}

M. Bhattacharya $\cdot$ D. Biswas $(\varangle) \cdot$ S. Sana $\cdot$ S. Datta Department of Chemical Technology, University of Calcutta, 92, A.P.C Road, Kolkata 700009, West Bengal, India e-mail: dipa_bis@yahoo.com
Keywords Biodegradation - Hydrocarbons - Waste engine oil · Waste transformer oil - Emulsification index

\section{Introduction}

The waste lubricating oil, otherwise called spent oil or used-lubricant, obtained after servicing and subsequent draining from automobiles, generators and industrial machines, is disposed off indiscriminately all over the world, and adequate attention has not been given to its disposal (Bartz 2006). This waste oil often contains appreciable amounts of EPA priority pollutants such as toxic heavy metals, polyaromatic hydrocarbons (PAHs), chlorinated hydrocarbons (PCBs) and other hydrocarbon contaminants that are known to have carcinogenic and neurotoxic effects on biological system (Ray et al. 2008; Chandra et al. 2013). Used oils can be re-refined to base lube oil by proper recycling process. But high contamination levels in waste oils increase the difficulties in recycling operation and as a result uncontrolled dumping in soil and drains and land filling of waste oils lead to environmental hazards with global implications (Misra and Pandey 2005; Lin et al. 2010). For environmental protection and to minimize pollution level, most of the industries follow the conventional thermal destruction process or acid-clay process to degrade the waste oils (USEPA 2004). But these are expensive, time-consuming and not environmentally safe procedures (Das and Chandran 2011). Bioremediation is the method of choice now-a-days due to its cost-effectiveness and wide environmental acceptability (Singh et al. 2009) that is based on simple microbial degradation phenomena by which complete removal of hydrocarbon pollutants can be done by using microorganisms (Gómez et al. 2007). Moreover, the ability of producing surface-active agents 
such as biosurfactants/bioemulsifiers is of major importance (Batista et al. 2006; Banat et al. 2010) that are directly involved in the process of hydrocarbon biodegradation from the environment through increased bioavailability and subsequent uptake of hydrophobic compounds by direct cell contact (Franzetti et al. 2010).

The base lubricating oil contains long chain $\left(\mathrm{C}_{16}-\mathrm{C}_{36}\right)$ saturated hydrocarbons and more than $75 \%$ cyclic alkanes (Koma et al. 2003) that are known as recalcitrant to microbial degradation. In addition, the presence of toxic metals, PAHs, etc. in used oil inhibits the microbial degradation process (Adesodun and Mbagwu 2008; Lee et al. 2008; Rauchyte et al. 2006). So, it is challenging to isolate a single microorganism having degrading potentials of diverse constituents of the base lube oil and effective for significant degradation of waste oils (Adebusoye et al. 2007; Ghazali et al. 2004). The microorganisms mostly isolated from hydrocarbon contaminated sites, having waste lubricating oil degrading ability, belong to the genera Pseudomonas, Rhodococcus, Alcaligenes, Acinetobacter, Arthrobacter, Citrobacter, Serratia, Micrococcus, Bacillus, etc. (Batista et al. 2006; Ron and Rosenberg 2014). Several results have been reported on biodegradation of petroleum hydrocarbons of waste motor lubricating oil-contaminated soils in recent times (Abioye et al. 2012; Aleer et al. 2011; Jain et al. 2010; Adesodun and Mbagwu 2008). But there are no such reports till date on waste lubricating oil degradation by Ochrobactrum sp. to the best of our knowledge.

Hence, our aim is to degrade the diverse range of hydrocarbons present in waste lubricating oil samples e.g., waste engine oil (WEO) and waste transformer oil (WTO) by an isolated culture of Ochrobactrum sp. $\mathrm{C} 1$, followed by the study of degradation efficiency of the strain and potential for surface-active compound production. Since biodegradation of waste oil is a natural process limited by several physicochemical factors (Chandra et al. 2013), optimization of the culture conditions has been carried out by response surface methodology (RSM) for enhanced biodegradation and a correlation between degradation and emulsification capability of the culture broth has also been established by this study.

\section{Materials and methods}

\section{Chemicals}

WEO (specific gravity-0.86) and WTO (specific gravity0.815) were collected from local automobile workshops and power generating stations nearby Kolkata, West Bengal, India. Fresh engine oil, transformer oil, gear oil, brake oil, diesel, kerosene were procured from retail market, and pure hydrocarbons were procured from Sigma Aldrich Co. USA. Other chemicals and solvents were of AR grade and purchased from Merck Co. Germany. Bushnell-Haas (BH) media and Nutrient agar media of Hi-Media Laboratories Pvt. Ltd were used for isolation, cultivation and maintenance of culture.

Isolation and selection of microorganism

Bushnell-Haas (BH) media with the following composition $(\mathrm{g} / \mathrm{L}): \mathrm{K}_{2} \mathrm{HPO}_{4}(1.0 \mathrm{~g}), \mathrm{KH}_{2} \mathrm{PO}_{4}(1.0 \mathrm{~g}), \mathrm{NH}_{4} \mathrm{NO}_{3}(1.0 \mathrm{~g})$, $\mathrm{MgSO}_{4} \cdot 7 \mathrm{H}_{2} \mathrm{O}(0.2 \mathrm{~g}), \mathrm{FeCl}_{3} \cdot 6 \mathrm{H}_{2} \mathrm{O}(0.05 \mathrm{~g}), \mathrm{CaCl}_{2} \cdot 2 \mathrm{H}_{2} \mathrm{O}$ $(0.02 \mathrm{~g})$, was used as enrichment medium with WEO as the sole carbon source to isolate waste lubricating oil degrading bacteria. Oil-contaminated soil samples were collected from 24 different locations including local automobile workshops, petroleum industry effluent area, and steel plant effluent area in and around Kolkata, India. Soil samples ( $\sim 10 \mathrm{gm})$ were added to $50 \mathrm{ml} \mathrm{BH}$ media taken in $250-\mathrm{ml}$ Erlenmeyer culture flasks with $2 \%(\mathrm{v} / \mathrm{v})$ waste oil and incubated at $37{ }^{\circ} \mathrm{C}$ at $100 \mathrm{rpm}$ in a rotary shaker incubator (ORBITEK-LJE, Scigenics Biotech Pvt. ltd., Chennai, India) for 7 days. After 7 days incubation, the cultures were isolated as single colony on to Nutrient Agar (NA) media by streak-plate method. They were maintained in slant cultures by preserving at $4{ }^{\circ} \mathrm{C}$ and subculturing at 2 weeks interval.

For selection of microorganism, the isolated cultures were screened for effective waste lubricating oil degrader as well as surface-active agent producer. Fresh overnight cultures $\left(\mathrm{OD}_{600}=1.0\right)$ suspended in $\mathrm{BH}$ media were used as inoculum $2 \%(\mathrm{v} / \mathrm{v})$ for all the experiments and inoculated aseptically in culture flasks with $2 \%(\mathrm{v} / \mathrm{v})$ carbon source at same culture conditions. After completion of the incubation period, the culture broth samples were centrifuged at 5,000 rpm (REMI R24) for $20 \mathrm{~min}$ and the culture supernatant was separated from the oil phase in a separating funnel. The culture supernatant was then evaluated for surface activity by measuring surface tension and emulsification index. The residual oil was measured for evaluating the degradation efficiency of the isolated microorganism. All the experiments were performed in triplicate, and a control devoid of the bacterial isolates was prepared for each set of experiments.

Identification of the selected microorganism C1

The genomic identification of the selected bacterial isolate was carried out by $16 \mathrm{~S}$ rRNA gene sequencing method from Bhat Biotech India Pvt. Ltd. Bangalore, India. DNA extraction was done using genomic DNA extraction Kit (Bhat Biotech), and PCR amplification of the $16 \mathrm{~s}$ rRNA gene was performed using the universal primers. The PCR 
products were sequenced by automated DNA sequencer$3037 x l$ DNA analyzer from Applied Biosystems using BigDye $^{\circledR}$ Terminator v3.1 cycle sequencing Kit (Applied Biosystems). Sequence data were aligned, and dendrograms were generated using Sequence analysis software version 5.2 from Applied Biosystems. Sequences were compared to the non-redundant NCBI database by using BLASTN, to find the most similar sequence, sorted by the E score. A representative sequence of 10 most similar neighbors was aligned using CLUSTAL W2 for multiple alignments with the default settings. The multiple-alignment file was then used to create phylogram using MEGA5 software.

\section{Biodegradation studies}

\section{Determination of degradation ability on different hydrocarbons}

Several hydrocarbons of naphthene-paraffin-aromatic (N$\mathrm{P}-\mathrm{A})$ series like nonane, dodecane, tetradecane, hexadecane, octadecane, eicosane, octacosane, decalin, tetralin, xylene, naphthalene, phenanthrene and anthracene were tested with the bacterial isolate to study its degradation ability of the type and range of hydrocarbons. Various petroleum fractions like lubricating oil base stock (LOBS), vacuum gas oil (VGO), diesel, kerosene and fresh lubricating oils like engine oil, transformer oil, brake oil, gear oil were also tested with the bacterial isolate to establish its degradation ability of different petroleum fractions from low boiling kerosene to high-boiling lubricating oils. All the hydrocarbons tested were at $2 \%(\mathrm{v} / \mathrm{v})$ concentration level at same culture parameters mentioned above.

\section{Determination of degradation ability on waste lubricating oils with varying culture conditions}

Waste lubricating oils namely WEO and WTO were treated with culture condition variations such as, incubation period (7, 14 and 21 days), $\mathrm{pH}$ (5, 7 and 9), incubation temperature $\left(32,37\right.$, and $\left.42{ }^{\circ} \mathrm{C}\right)$ and oil concentration $(2,5$ and $10 \% \mathrm{v} / \mathrm{v}$ ) to study the effect on waste oil percent degradation ability of the culture.

\section{Biodegradation analysis}

\section{Bacterial growth determination}

The biomass concentration in the culture broth was determined by dry weight method. In this method, the broth was centrifuged at 5,000 rpm for $20 \mathrm{~min}$. The bacterial mass was then transferred to a pre-weighted aluminum cup and dried at $50{ }^{\circ} \mathrm{C}$ overnight. The exact weight of the bacterial mass was determined by subtracting the weight of dry cup from that of the cup containing dry bacterial mass. The cell concentrations were also determined using spectrophotometer at $600 \mathrm{~nm}$.

\section{Hydrocarbon analysis using gas chromatography}

The residual oil sample from inoculated and un-inoculated culture flasks was extracted three times with hexane after each biodegradation experiment according to Adebusoye et al. (2007). The organic phase was concentrated by evaporation of the solvent after drying over anhydrous $\mathrm{Na}_{2} \mathrm{SO}_{4}$ and analyzed by gas chromatography according to the condition described by Ghazali et al. (2004). Hexane extracts of residual oil sample $(1 \mu \mathrm{l})$ were injected for analysis by using a Polaris Q Mass Spectrometer coupled with Thermo Scientific Trace 1300 series gas chromatograph and TR-5 column $\left(30 \times 10^{3} \mathrm{~cm}\right.$ length; $0.032 \mathrm{~cm}$ id; and $1 \times 10^{-3} \mathrm{~cm}$ film thickness). Nitrogen was used as carrier gas. The injector and detector temperatures were maintained at 300 and $280{ }^{\circ} \mathrm{C}$, respectively. The oven was programmed at an initial temperature of $40{ }^{\circ} \mathrm{C}$; this was held for $2 \mathrm{~min}$, then ramped at $15^{\circ} \mathrm{C} / \mathrm{min}$ to $300{ }^{\circ} \mathrm{C}$ and held for $10 \mathrm{~min}$. The relative percent degradation of WEO and WTO was calculated by the differences in summation of peak area of total petroleum hydrocarbons (TPH) present in the residual oil compared to that from un-inoculated control flasks (Bhattacharya and Biswas 2014a). Degradation efficiency of pure hydrocarbons was also calculated by the differences in summation of peak area compared to their respective standards. Chromatographs were analyzed by Chromeleon 7.0 program and a library (NIST 2007) search was performed for identification of chromatogram peaks.

\section{Surface tension measurement}

Surface tension of cell-free and oil-free culture supernatant was measured by the application of a digital tensiometer (Dataphysics DCAT 11, Germany) at $30{ }^{\circ} \mathrm{C}$ using du Nouy ring method (Lunkenheimer and Wantke 1981).

\section{Emulsification index measurement}

Emulsification index $\left(E_{24}\right)$ was measured following the method described by Cooper and Goldenberg (1987). Two milliliters of engine oil was added to $2 \mathrm{ml}$ of cell-free extract and vortexed at high speed for $2 \mathrm{~min}$. Diesel, kerosene, crude oil and transformer oil were also used as substrate for emulsification. Measurements were taken after $24 \mathrm{~h}$ as follows: 
$E_{24}=$ (height of the emulsion/total height $) \times 100$

Optimization studies using response surface methodology

Preliminary trials indicated that $\mathrm{pH}$, temperature and waste oil concentration in the culture medium were the significant variables for the percentage biodegradation of waste oils. Hence, $\mathrm{pH}$, temperature and waste oil concentration were chosen as the three variables for optimization studies. The three levels of each variable are given in Table 1. Percent degradation of WEO and $E_{24}$ values was taken as two responses.

A $3^{3}$ Box-Behnken experimental design was carried out with three replicates at the center points leading to 15 runs. The variables were coded according to the following equation:

$x_{i}=\left(X_{i}-X_{0}\right) / \Delta X \quad i=1,2,3 \ldots k$

where $x_{i}$ is the dimensionless value of an independent variable, $X_{i}$ is the real value of an independent variable, $X_{0}$ is the value of $x_{i}$ at the center point, and $\Delta X$ is the step change value.

The second-order polynomial model was fitted to response giving an equation term:

$\tilde{Y}_{i}=\beta_{0}+\sum_{i=1}^{3} \beta_{i} x_{i}+\sum_{i=1}^{3} \beta_{i i} x_{i}^{2}+\sum_{i, j=1}^{3} \beta_{i j} x_{i} x_{j}$

Table 1 Box-Behnken design for the three independent variables on biodegradation of waste engine oil and corresponding $E_{24}$ of the culture broth

\begin{tabular}{lllllll}
\hline Runs & $\begin{array}{l}X_{1} \\
\text { (temperature } \\
\left.{ }^{\circ} \mathrm{C}\right)\end{array}$ & $\begin{array}{l}X_{2} \\
(\mathrm{pH})\end{array}$ & $\begin{array}{l}X_{3} \text { (oil } \\
\text { conc. v/v } \\
\%)\end{array}$ & $\begin{array}{l}E_{24} \\
\text { value } \\
(\%)\end{array}$ & $\begin{array}{l}\text { Percent degradation } \\
(\%) \text { of } \mathrm{WEO}^{\mathrm{a}}\end{array}$ \\
\hline 1 & 34 & 6 & 5 & 42.63 & 26.32 & 26.68 \\
2 & 40 & 6 & 5 & 40.2 & 16.14 & 15.12 \\
3 & 34 & 8 & 5 & 52.5 & 40.36 & 41.88 \\
4 & 40 & 8 & 5 & 50.24 & 32.43 & 30.32 \\
5 & 34 & 7 & 3 & 54.75 & 42.5 & 43.26 \\
6 & 40 & 7 & 3 & 50.5 & 32.67 & 31.7 \\
7 & 34 & 7 & 7 & 55 & 42.43 & 39.10 \\
8 & 40 & 7 & 7 & 41 & 24.31 & 27.54 \\
9 & 37 & 6 & 3 & 52.9 & 34.25 & 32.30 \\
10 & 37 & 8 & 3 & 58.63 & 45.34 & 47.5 \\
11 & 37 & 6 & 7 & 50 & 26.25 & 28.15 \\
12 & 37 & 8 & 7 & 60.52 & 45.7 & 43.34 \\
13 & 37 & 7 & 5 & 72.4 & 56.21 & 55.08 \\
14 & 37 & 7 & 5 & 70.67 & 54.25 & 55.08 \\
15 & 37 & 7 & 5 & 71.68 & 55.43 & 55.08 \\
\hline
\end{tabular}

${ }^{\text {a }}$ All values are represented as (mean \pm SD) based on triplicate assays where $\tilde{\mathrm{Y}}_{i}$ is the predicted response, $x_{i}$ and $x_{j}$ are the input variables, $\beta_{0}$ is the intercept term, $\beta_{i}$ is the linear effects, $\beta_{i i}$ is the squared effects, and $\beta_{i j}$ is the interaction term.

'Statistica v. 10' software was used for regression and graphical analysis of the data. The optimum values of culture condition variables $(\mathrm{pH}$, temperature and oil concentration) were obtained by solving the regression equation and analyzing the response surface contour plots.

\section{Results and discussion}

Isolation and identification of microorganism

Twenty-four bacterial strains were isolated and tested for waste lubricating oil degrading ability and emulsification ability (Fig. 1) among which only strain C1 was selected for its best degrading efficiency of WEO and $E_{24}$ values using engine oil as substrate. This strain is an aerobic, gram-negative short rod. Sequence analysis of the $16 \mathrm{~S}$ rRNA gene revealed $93 \%$ homology with Ochrobactrum pseudintermedium strain ADV31. The phylogenetic tree generated using Neighbor-Joining method was provided in Fig. 2. The sequence has been submitted to GenBank with the accession no. KJ094035. Thus, our isolated strain C1 should be classified as a strain of Ochrobactrum sp. C1. The genus Ochrobactrum has been reported to degrade phenanthrene (Ghosal et al. 2010), phenol (Kılıç 2009), nicotine (Yuan et al. 2006), methyl parathion (Qiu et al. 2007), and various hydrocarbons (Calvo et al. 2008). Our study extended its application to the degradation of waste lubricating oil.

\section{Degradation characteristics of the strain $\mathrm{C} 1$}

\section{Biodegradability of hydrocarbons of $N-P-A$ series}

The hydrocarbon utilization was performed with various hydrocarbon substrates to find out some insight about the substrate specificity for hydrocarbon biodegradation by Ochrobactrum sp. $\mathrm{C} 1$ as shown in Fig. 3a. The strain could metabolize linear $n$-alkanes ranging from $\mathrm{C}_{12}-\mathrm{C}_{28}$, but degradation efficiency was found to be decreased as alkane chain length increased as reported by several other researchers (Wang et al. 2011; Zhang et al. 2011). The losses affected by abiotic process during the incubation period were greater with the lower molecular mass alkanes than the alkanes of longer chain length. Among the aromatics, xylene and naphthalene were vaporized during period of incubation and the strain was only found to metabolize the PAHs when grown with phenanthrene and anthracene. Degradation efficiency was also higher with n-alkanes than the PAHs as represented in Fig. 3a. The strain could not 
Fig. 1 Screening of waste lubricant degrader microorganism from different oil-contaminated soil samples
Fig. 2 Phylogenetic tree showing interrelationship of isolated strain $\mathrm{C} 1$ with closely related species of the different genera inferred from 16S rRNA sequences. The tree was generated using the NeighborJoining method

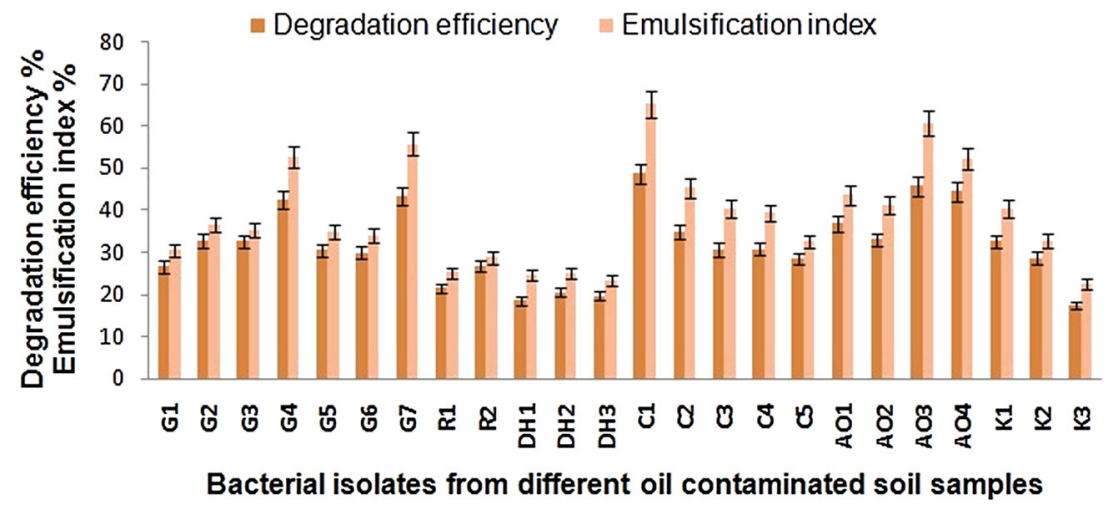

metabolize decalin and tetralin from naphthene series probably due to microbial toxicity of these compounds (Sikkema et al. 1995).

\section{Biodegradability of petroleum fractions and synthetic lubricants}

More than $70 \%$ degradation of the petroleum fractions was observed (Fig. 3a), which suggests that the strain is very much efficient for biodegradation of waste petroleum. Selective degradation of synthetic lubricants was also observed by the strain within 7 days incubation period. The lubricant removal efficiency of each strain was influenced by the types of lubricant. Montagnolli et al. (2009) reported that mineral lubricant is the most biodegradable, followed by semi-synthetic and synthetic lubricant.

Waste lubricant degradation in pure culture

The initial concentrations of WEO and WTO used for biodegradation studies were $2 \%(\mathrm{v} / \mathrm{v})$, i.e., 17,200 and $16,300 \mathrm{mg} \mathrm{L}^{-1}$, respectively. Percentage degradation by Ochrobactrum sp. C1 was found to be $48.5 \pm 0.50 \%$ for WEO and $30.47 \pm 0.25 \%$ for WTO at temperature $37^{\circ} \mathrm{C}$, pH 7 and 7 days incubation period. During the incubation period, an emulsification of the WEO was observed in the culture broth, which suggests that the production of extra cellular bioemulsifier may be one of the mechanisms used by the present isolate in the utilization of WEO. Obayori et al. (2009) also reported similar type of emulsification capability of the culture supernatant by Pseudomonas sp. LP1 when grown on waste motor lubricating oil. The cellfree culture supernatant showed no significant reduction in surface tension of water $(72 \pm 0.15$ to $55 \pm 0.27 \mathrm{mN} / \mathrm{m})$, but it showed emulsification ability toward various oils including kerosene, diesel, crude oil and engine oil. Emulsification index was found to be much higher $\left(E_{24}\right.$ $65 \pm 0.32 \%$ ) using engine oil as substrate.

\section{Effect of oil concentration}

The degradation of WEO and WTO at various initial levels $(2,5$ and $10 \% \mathrm{v} / \mathrm{v})$ was examined in $\mathrm{BH}$ medium at $\mathrm{pH} 7.0$ and $37{ }^{\circ} \mathrm{C}$ over 7 days incubation period (Fig. 3b). No significant reduction in oil was observed for all controls. The percentage degradation was $48.83 \pm 0.31,52.3 \pm$ 0.36 and $45.5 \pm 0.40 \%$, respectively, for WEO. The result is in agreement with the findings of Abioye et al. (2012) who reported 3-6\% as the concentration of used motor oil for maximum rate of biodegradation. For WTO, the percentage degradation was $30.43 \pm 0.80,27.32 \pm 0.64$ and $18.74 \pm 0.60 \%$, respectively. It was observed that the percentage degradation of WTO was decreased with increasing oil concentration and was much lower than the

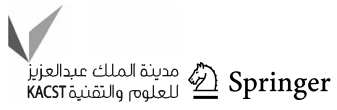




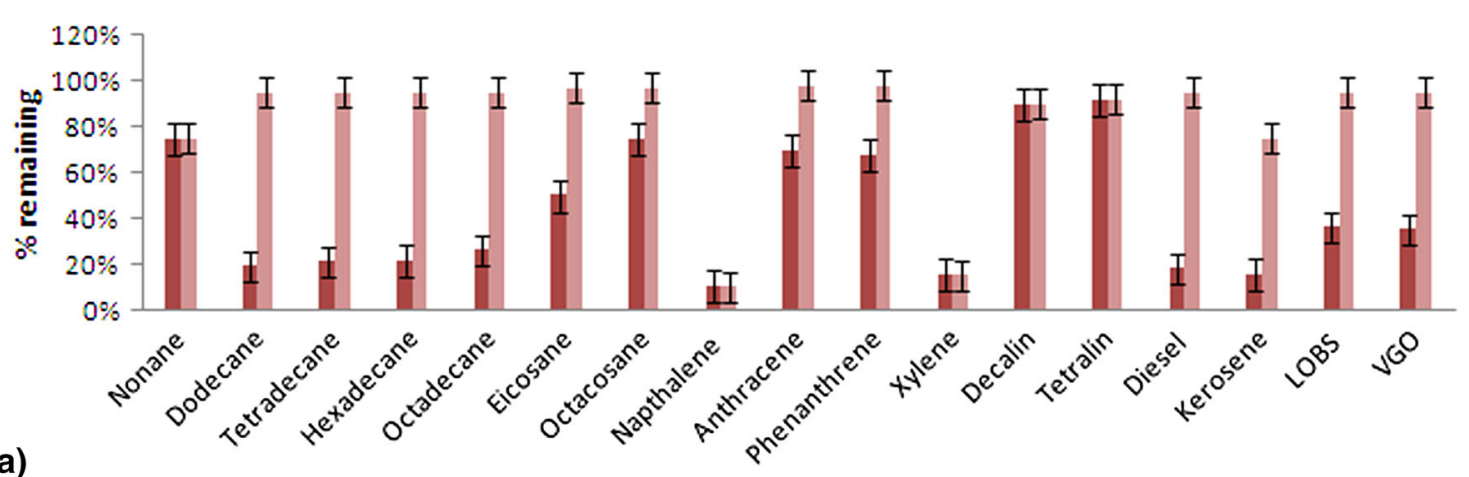

Hydrocarbon source

n Inoculated cultures Uninoculated control

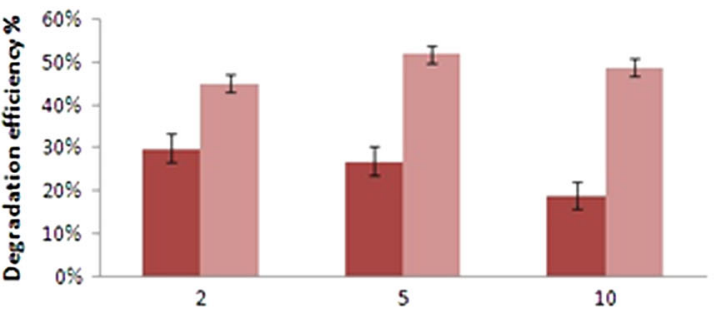

(b)

Waste oil concentration $\%(w / v)$

w WTO degradation efficiency $=$ WEO degradation efficiency

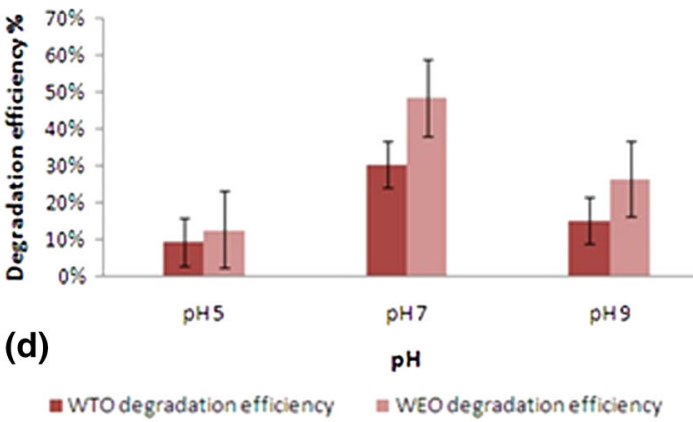

Fig. 3 Hydrocarbon degradation characteristics and degradation efficiency of WEO and WTO by Ochrobactrum sp. C1 with $2 \%$ $(\mathrm{v} / \mathrm{v})$ initial concentration of carbon source at $\mathrm{pH} 7.0$, temperature $37{ }^{\circ} \mathrm{C}$ and 7 days incubation period. a Degradation percentage of different hydrocarbons; $\mathbf{b}$ effect of initial waste oil concentrations on percent degradation of WEO and WTO (at constant temperature, $\mathrm{pH}$ and incubation period); $\mathbf{c}$ effect of incubation period on percent

degradation efficiency of WEO, possibly due to the presence of highly persistent chlorinated alkanes as reported by Molnar et al. (2005).

\section{Effect of incubation period}

The effect of increasing incubation period from 7, 14 and 21 days was checked to find out the maximum extent of degradation efficiency at same culture parameters with $2 \%$ $(\mathrm{v} / \mathrm{v})$ waste oil concentrations. It was found that percentage degradation increased from $48.35 \pm 0.37$ to $63.5 \pm$
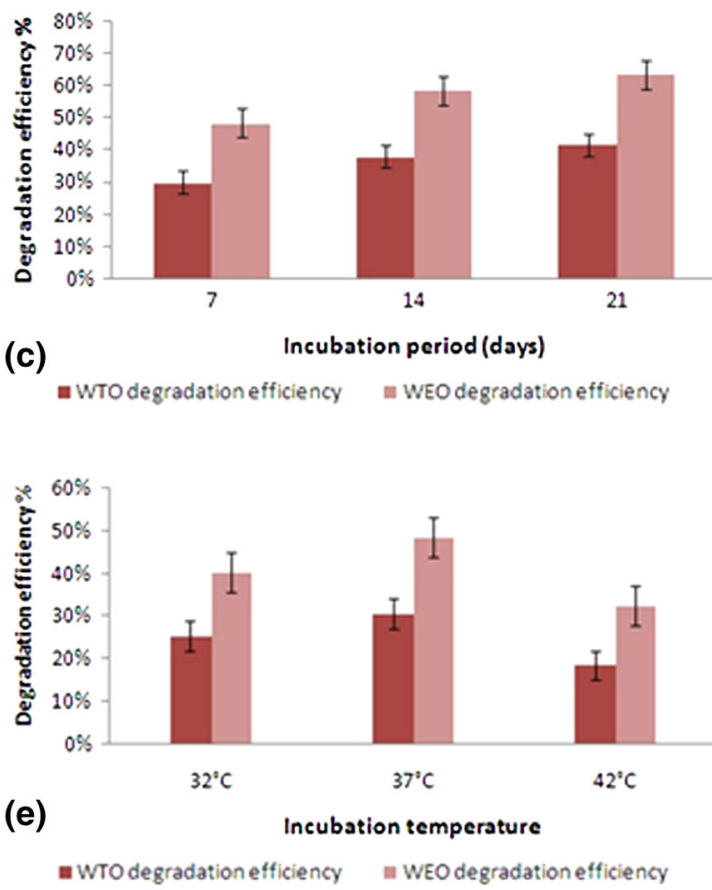

degradation of WEO and WTO (at constant $\mathrm{pH}$, temperature and waste oil concentration); $\mathbf{d}$ effect of initial medium $\mathrm{pH}$ on percent degradation of WEO and WTO (at constant temperature, incubation period and waste oil concentration); e effect of incubation temperature on percent degradation of WEO and WTO (at constant $\mathrm{pH}$, incubation period and waste oil concentration); Error bars, mean \pm SD of three replicates

$0.50 \%$ for WEO and $30.74 \pm 0.42$ to $41.5 \pm 0.48 \%$ for WTO on increasing the incubation period from 7 to 21 days (Fig. 3c). Bacterial growth is slower on insoluble hydrocarbon substrates due to less bioavailability, and it is one of the major constraints in bioremediation experiments. Several other researchers (Ghazali et al. 2004; Wang et al. 2011; Abioye et al. 2012) also found that TPH levels could be significantly reduced with longer incubation period during treatment of waste oil-contaminated soil. Biswal et al. (2009) reported that 40-50\% degradation of diesel engine lubricating oil could be achieved within 7 days. 


\section{Effect of $\mathrm{pH}$}

The degradation of WEO and WTO at various initial $\mathrm{pH}$ levels $(5,7$ and 9) were tested in $\mathrm{BH}$ medium with $2 \%$ (v/v) oil concentration at $37{ }^{\circ} \mathrm{C}$ over 7 days incubation period (Fig. 3d). As shown, when the $\mathrm{pH}$ was 5.0, 7.0 and 9.0 , percentage degradation of WEO were $12.82 \pm 0.24$, $48.56 \pm 0.37,26.54 \pm 0.20 \%$ and percentage degradation of WTO were $9.37 \pm 0.30, \quad 30.63 \pm 0.41, \quad 15.42 \pm$ $0.26 \%$, respectively. Only abiotic loss was observed for all controls. The results indicated that near-neutral condition was favorable for the degradation of waste lubricants by strain $\mathrm{C} 1$, whereas higher or lower $\mathrm{pH}$ inhibited degradation. The results were consistent with the findings of Jain et al. (2010), who also found that near neutral $\mathrm{pH}$ was most favorable for degradation of petroleum hydrocarbons in crude oil.

\section{Effect of temperature}

The effect of incubation temperature on biodegradation of WEO and WTO in BH medium with $2 \%(\mathrm{v} / \mathrm{v})$ oil concentration, $\mathrm{pH} 7.0$ and 7 days incubation period. Abiotic percentage loss of waste oils was observed for all controls. As shown in Fig. 3e, percentage degradation of WEO was $40.34 \pm 0.27,48.46 \pm 0.32$ and $32.51 \pm 0.30 \%$ for 32 ,
37 and $42{ }^{\circ} \mathrm{C}$, respectively, whereas percentage degradation of WTO were found to be $25.35 \pm 0.34,30.57 \pm 0.29$ and $18.52 \pm 0.31 \%$ for temperatures 32,37 and $42{ }^{\circ} \mathrm{C}$, respectively. The results indicated that the optimum temperature for biodegradation of waste lubricants by strain $\mathrm{C} 1$ in pure culture was $37^{\circ} \mathrm{C}$. Aleer et al. (2011) also found that $30-37^{\circ} \mathrm{C}$ was the optimum temperature for WEO biodegradation by a microbial consortium.

Optimization of culture conditions

The effects of three variables viz. $\mathrm{pH}$, temperature and oil concentration on percent degradation of WEO were studied to achieve optimum biodegradation within 7 days incubation period. The optimum values were determined using the Box-Behnken experimental design matrix presented in Table 1. Analyzing these data by multiple regressions, the following quadratic polynomial equation was found to express the percentage degradation of WEO:

$$
\begin{aligned}
\widetilde{Y}_{i}= & 33.91-10.71 X_{1}+15.13 X_{2}-4.23 X_{3}+14.5 X_{1}^{2} \\
& +12.08 X_{2}^{2}+5.18 X_{3}^{2}+1.00 X_{1} X_{2}-4.3 X_{1} X_{3} \\
& +4.31 X_{2} X_{3}
\end{aligned}
$$

where $\tilde{Y}_{i}$ is the predicted percent degradation, $X_{1}$ temperature, $X_{2} \mathrm{pH}$ and $X_{3}$ waste oil concentration.

\begin{tabular}{|c|c|c|c|c|c|c|}
\hline Factor & Coefficient (std. error) & Sum of squares & $d f^{\mathrm{a}}$ & $F$ value $^{\text {b }}$ & Computed $t$ value $t(2)$ & $p$ value* Prob $>F^{\mathrm{c}}$ \\
\hline Intercept & $33.91(0.25)$ & & & & 133.78 & $0.000056^{*}$ \\
\hline$X_{1}(\mathrm{~L})$ & $-10.71(0.65)$ & 277.662 & 1 & 360.210 & -16.37 & $0.002765 *$ \\
\hline$X_{1}^{2}(\mathrm{Q})$ & $15.13(0.65)$ & 776.620 & 1 & $1,007.507$ & 23.12 & $0.000991 *$ \\
\hline$X_{2}(\mathrm{~L})$ & $-4.23(0.65)$ & 419.345 & 1 & 544.015 & -6.46 & $0.001833 *$ \\
\hline$X_{2}^{2}(\mathrm{Q})$ & $14.5(0.46)$ & 538.842 & 1 & 699.039 & 31.74 & $0.001427 *$ \\
\hline$X_{3}(\mathrm{~L})$ & $12.08(0.46)$ & 30.062 & 1 & 38.999 & 26.44 & $0.024696^{*}$ \\
\hline$X_{3}^{2}(\mathrm{Q})$ & $5.18(0.46)$ & 99.089 & 1 & 128.548 & 11.34 & $0.007690 *$ \\
\hline$X_{1} X_{3}(1 \mathrm{~L}$ by $3 \mathrm{~L})$ & $1.00(0.88)$ & 18.490 & 1 & 23.987 & 1.14 & $0.039251 *$ \\
\hline$X_{1} X_{2}(1 \mathrm{~L}$ by $2 \mathrm{~L})$ & $-4.3(0.88)$ & 13.158 & 1 & 17.070 & -4.89 & 0.053889 \\
\hline$X_{2} X_{3}(2 \mathrm{~L}$ by $3 \mathrm{~L})$ & $4.31(0.88)$ & 18.533 & 1 & 24.043 & 4.9 & $0.039165 *$ \\
\hline $2 \mathrm{~L}$ by $3 \mathrm{Q}$ & & 0.078 & 1 & 0.101 & & 0.780534 \\
\hline $2 \mathrm{Q}$ by $3 \mathrm{~L}$ & & 0.090 & 1 & 0.117 & & 0.764757 \\
\hline Lack of fit & & 1.000 & 1 & 1.297 & & 0.372750 \\
\hline Pure error & & 1.542 & 2 & & & \\
\hline Total SS & & $2,080.269$ & 14 & & & \\
\hline
\end{tabular}

Table 2 Analysis of variance (ANOVA) for biodegradation of waste engine oil and model coefficients estimated by multiple linear regression analysis

$R^{2}=0.99878$

Adjusted $R^{2}=0.9943$

$* p<0.05$ are considered to be significant

${ }^{\mathrm{a}}$ Degree of freedom

b Test for comparing model variance with residual (error) variance

c Probability of seeing the observed $F$ value if the null hypothesis is true 
(a)

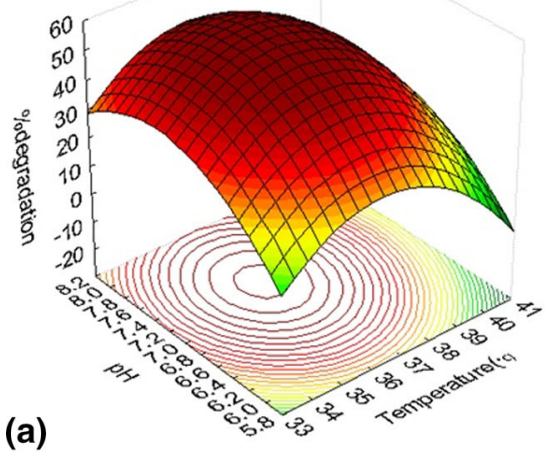

(b)

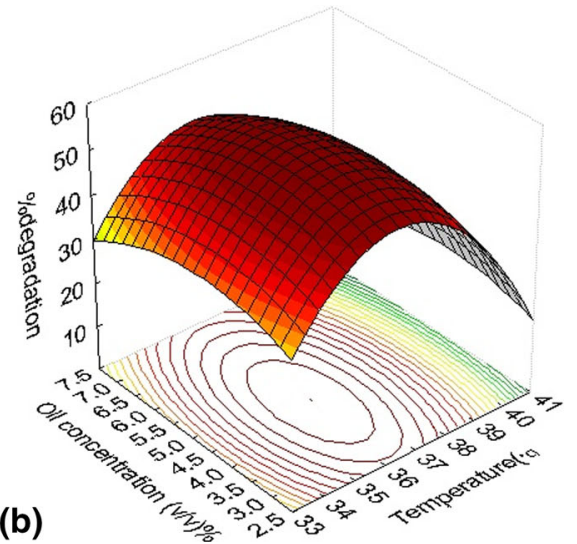

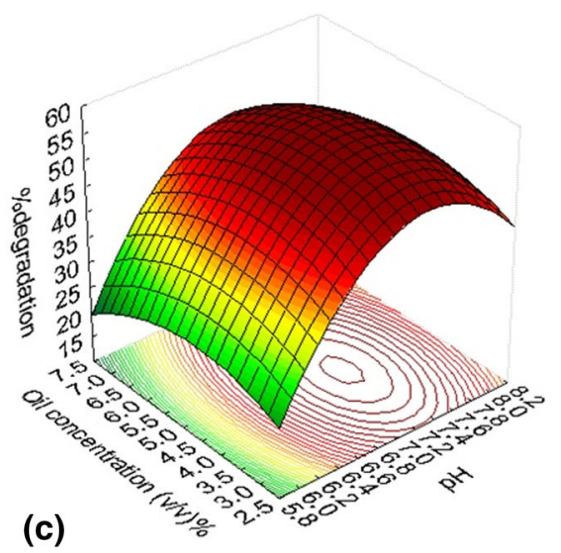

Fig. 4 Response surface plots for degradation of WEO by Ochrobactrum sp. $\mathrm{C} 1 \mathbf{a}$ effects of temperature and $\mathrm{pH}$; $\mathbf{b}$ effects of temperature and oil concentration; $\mathbf{c}$ effects of oil concentration and $\mathrm{pH}$

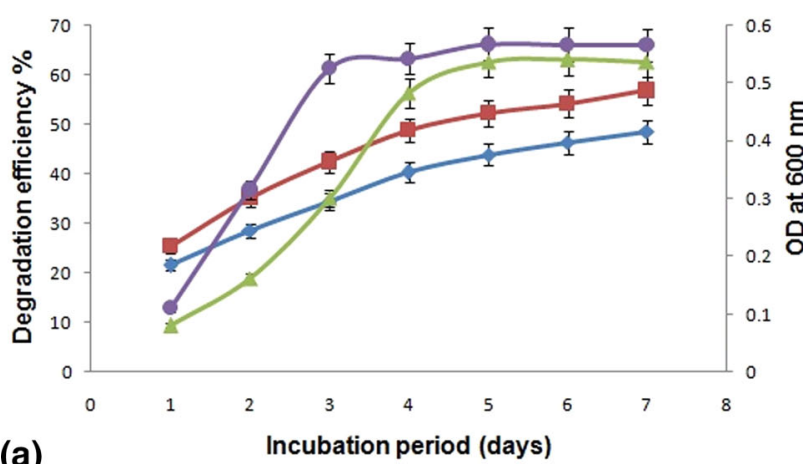

(a)

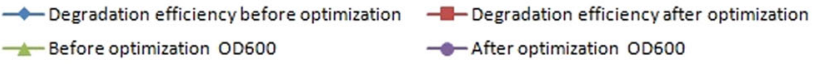

Fig. 5 Validation experiment for biodegradation of WEO a degradation efficiency and culture density before and after optimization by Ochrobactrum sp. C1 over incubation period of 7 days; $\mathbf{b}$ correlation

ANOVA results of the second-order response surface model summarized in Table 2. Fischer's $F$ test was performed on experimental data to evaluate the statistical significance of the model. According to ANOVA, the $F$ values for all regressions were high, indicated that most of the variations on the response variables can be explained by the regression equation. A $p$ value lower than 0.05 indicated that the model is considered to be statistically significant (Myers and Montgomery 2002). Goodness of fit was examined by the correlation coefficient $\left(R^{2}=0.998\right)$ between the experimental and modeled data represented in Table 1, which revealed a linear mathematical relation among them confirming the adequacy of the regression model. The mathematical adjust of these values considering residual error generated a $R^{2}$ (adjusted) $=0.9943$, revealing that only $0.57 \%$ of the overall effects could not be

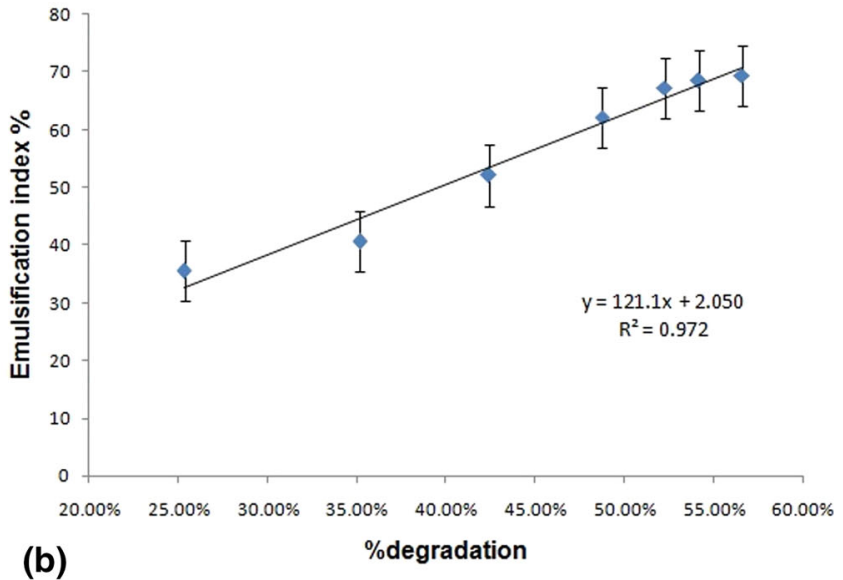

between percent degradation and emulsification index of culture broth; Error bars, mean $\pm \mathrm{SD}$ of three replicates

explained by the model which again shows the model to be highly significant. In addition the mismatching analysis $\left(P_{\text {lack of fit }}=0.37\right)$ was observed to be insignificant, implying that the obtained model was adequate to explain the experimental data.

The significance of each coefficient of the model was determined by Student's $t$ test and $p$ value (Table 2). Larger magnitude of $t$ test and smaller $p$ value was indicative of a more significant coefficient effect (Myers and Montgomery 2002). It was observed that the linear and quadratic effects of all three parameters and the interaction effects between temperature-oil concentration and $\mathrm{pH}-\mathrm{oil}$ concentration were significant with a $p$ value $<0.05$.

The 3D response surface plots described by the regression model were drawn to illustrate the effects of the independent variables, and combined effects of each 
Fig. 6 GC chromatogram of waste oil samples. a WEO residual oil sample extracted before and after biodegradation experiment; b WTO residual oil sample extracted before and after biodegradation experiment
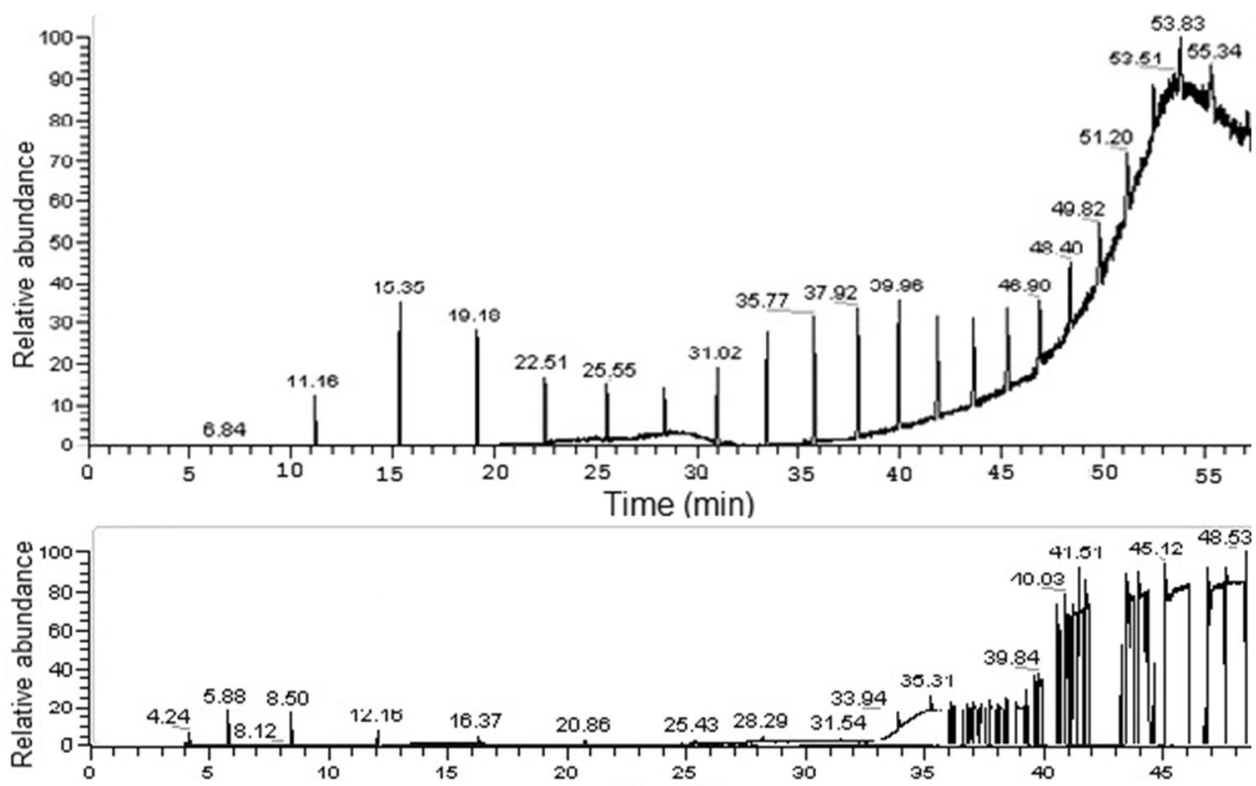

(a)

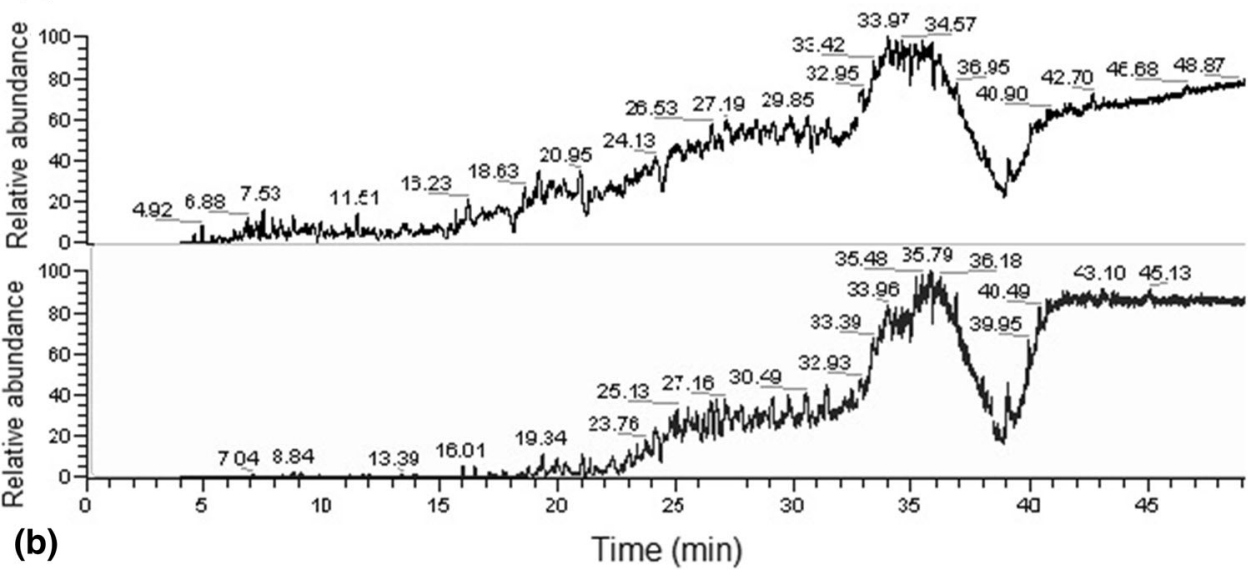

independent variable upon the response variable. Figure $4 \mathrm{a}-\mathrm{c}$ represents the $3 \mathrm{D}$ response surface plots for the optimum culture conditions of waste engine oil degradation. Each figure presents the effect of two variables, while the third was held at zero. To determine the optimized culture condition, the optimal values of the variables $X_{1}, X_{2}$ and $X_{3}$ were found out by solving the regression equation. This was achieved by putting the second-order regression equation into matrix form as described by Myers and Montgomery (2002). The model predicted that with temperature $36.4{ }^{\circ} \mathrm{C}, \mathrm{pH} 7.3$ and waste oil concentration $4.6 \%$ (v/v), the maximum percent degradation rate will be $57 \%$.

Biodegradation of WEO at optimized culture conditions

Subsequent experiments with the optimized culture condition yielded significant results of $56.7 \pm 0.25 \%$ removal of WEO with an initial concentration of $4.6 \%$ (v/v), i.e., $39,560 \mathrm{mg} \mathrm{L}^{-1}$ within 7 days, which is also consistent with the prediction. Figure 5a showed the percentage degradation of WEO and bacterial culture density before and after optimization of culture parameters over 7 days incubation period, which indicates positive enhancement of growth and biodegradation efficiency of the strain Ochrobactrum sp. $\mathrm{C} 1$., whereas Fig. 5b represented a good correlation between rate of percent degradation and emulsification activity (highest $E_{24}=69.42 \pm 0.32 \%$ ) of the culture broth with a correlation coefficient $r=0.972$, indicating that the uptake of waste oil might be enhanced due to production of emulsifying agent by Ochrobactrum sp. C1. The production, isolation and characterization of the emulsifying agent have also been reported previously by Bhattacharya et al. (2014b). Similar findings were also reported by Mehdi and Giti (2008) about correlation between biofilm formation, biosurfactant production and crude oil biodegradation. Hua and Wang (2012) also found a positive correlation exists between surface-active agent production and uptake of octadecane by Pseudomonas sp. DG 17. 
Characterization of waste lubricating oils

Waste lubricating oils may have highly variable compositions according to the extent of combustion process during its functioning, so the biodegradation analysis was done by comparing the content of recoverable total petroleum hydrocarbons (TPH) from influent and effluent oil samples. The GC spectra of hydrocarbon compounds occurring in both the treated and untreated waste oil samples, i.e., WEO and WTO, were expressed in Fig. 6a, b. Both the waste oil samples after biological treatment, revealed significant reduction in major hydrocarbon peaks compared to those from untreated control samples. The most abundant peaks from WEO were identified as derivatives of benzene, naphthalene, azulene, indole, benzopyrene, dibenzophenazine, etc., whereas the compounds identified from WTO sample, mostly consisted biphenyl and naphthene derivatives. Benzene-based compounds and naphthalenerelated components are the predominant hydrocarbon structures in the composition of both the waste lubricating oil samples. Naphthalene, acenaphthylenes, diphenylanthracenes, benzopyrene and benzanthracene were also detected in used motor oil samples by several other researchers (Koma et al. 2003; Wang et al. 2010). In addition, it was also observed from Fig. 6 that low molecular weight benzene derivatives were better removed by strain C1 than the high molecular weight benzene derivatives according to their relative abundance, in which the point was also supported by Genov et al. (2008).

\section{Conclusion}

A newly isolated Ochrobactrum sp. C1 could grow with waste lubricants as the sole carbon and energy source and degrade a wide range of hydrocarbons present in waste lubricants efficiently. The culture parameters were optimized using response surface methodology and the optimized culture condition (temperature $36.4{ }^{\circ} \mathrm{C}, \mathrm{pH} 7.3$ and $4.6 \%(\mathrm{v} / \mathrm{v})$ oil concentration) yielded significant results of $56.7 \pm 0.25 \%$ removal of WEO within 7 days. Moreover, the culture showed high emulsification capability toward a range of hydrocarbons, among which the highest emulsification index $\left(E_{24}=69.42 \pm 0.32 \%\right)$ was obtained with engine oil after 7 days incubation period at optimized culture condition. Therefore, biodegradation and optimization studies with Ochrobactrum sp. C1 may be of great significance in bioremediation of highly contaminated soils or sewage sludge with waste lubricants in bioreactor systems.

Acknowledgments The first author thankfully acknowledge for the research assistantship provided by TEQIP-II (Technical Education
Quality Improvement Programme) and Mr. Smritiranjan Majhi from Central Instrument Facility Laboratory, Bose Institute, Kolkata (West Bengal), India for the technical support in GC-MS analysis.

Conflict of interest The authors declare that they have no conflict of interest in the publication.

Open Access This article is distributed under the terms of the Creative Commons Attribution License which permits any use, distribution, and reproduction in any medium, provided the original author(s) and the source are credited.

\section{References}

Abioye PO, Agamuthu P, Aziz AR (2012) Biodegradation of used motor oil in soil amended with organic wastes. Biotechnol Res Int. doi: $10.1155 / 2012 / 587041$

Adebusoye SA, Ilori MO, Amund OO, Teniola OD, Olatope SO (2007) Microbial degradation of petroleum hydrocarbons in a polluted tropical stream. World J Microb Biotechnol 23:1149-1159

Adesodun JK, Mbagwu JSC (2008) Biodegradation of waste-lubricating petroleum oil in a tropical alfisol as mediated by animal droppings. Bioresour Technol 99:5659-5665

Aleer S, Adetutu EM, Makadia TH, Patil S, Ball AS (2011) Harnessing the hydrocarbon-degrading potential of contaminated soils for the bioremediation of waste engine oil. Water Air Soil Poll 218:121-130

Banat IM, Franzetti A, Gandolfi I, Bestetti G, Martinotti MG, Fracchia L, Smyth TJP, Marchant R (2010) Microbial biosurfactants production, applications and future potential. Appl Microbiol Biotechnol 87:427-444

Bartz WJ (2006) Ecotribology: environmentally acceptable tribological practices. Tribol Int 39:728-733

Batista SB, Mounteer AH, Amorim FR, Totola MR (2006) Isolation and characterization of biosurfactant/bioemulsifier-producing bacteria from petroleum contaminated sites. Bioresour Technol 97:868-875

Bhattacharya M, Biswas D (2014) Enhancement of waste engine oil biodegradation by optimization of media using factorial design study. Indian J Biotechnol 13:293-300

Bhattacharya M, Biswas D, Sana S, Datta S (2014) Utilization of waste engine oil by Ochrobactrum pseudintermedium strain $\mathrm{C} 1$ that secretes an exopolysaccharide as a bioemulsifier. Biocatal Agric Biotechnol 3:167-176

Biswal BK, Tiwari SN, Mukherji S (2009) Biodegradation of oil in oily sludges from steel mills. Bioresour Technol 100:1700-1703

Calvo C, Silva-Castro GA, Uad I, Fandiño CG (2008) Efficiency of the EPS emulsifier produced by Ochrobactrum anthropi in different hydrocarbon bioremediation assays. J Ind Microbiol Biotechnol 35:1493-1501

Chandra S, Sharma R, Singh K, Sharma A (2013) Application of bioremediation technology in the environment contaminated with petroleum hydrocarbon. Ann Microbiol 63:417-431

Cooper DG, Goldenberg BG (1987) Surface-active agents from two Bacillus species. Appl Environ Microbiol 53:224-229

Das N, Chandran P (2011) Microbial degradation of petroleum hydrocarbon contaminants-an overview. Biotechnol Res Int 2011:1-13. doi:10.4061/2011/941810

Franzetti A, Tamburini E, Banat IM (2010) Applications of biological surface active compounds in remediation technologies. Biosurfactants 672:121-134

Genov G, Nodland E, Skaare BB, Barth T (2008) Comparison of biodegradation level and gas hydrate plugging potential of crude 
oils using FT-IR spectroscopy and multi-component analysis. Org Geochem 39:1229-1234

Ghazali FM, Rahman RNZA, Salleh AB, Basri M (2004) Biodegradation of hydrocarbons in soil by microbial consortium. Int Biodeterior Biodegrad 54:61-67

Ghosal D, Chakraborty J, Khara P, Dutta TK (2010) Degradation of phenanthrene via meta-cleavage of 2-hydroxy-1-naphthoic acid by Ochrobactrum sp. strain PWTJD. FEMS Microb Lett 313:103-110

Gómez MJ, Pazos F, Guijarro FJ, de Lorenzo V, Valencia A (2007) The environmental fate of organic pollutants through the global microbial metabolism. Mol Syst Biol 3:1-11

Hua F, Wang H (2012) Uptake modes of octadecane by Pseudomonas sp. DG17 and synthesis of biosurfactant. J Appl Microbiol 112:25-37

Jain PK, Gupta VK, Pathak H, Lowry M, Jaroli DP (2010) Characterization of $2 \mathrm{~T}$ engine oil degrading indigenous bacteria, isolated from high altitude (Mussoorie), India. World J Microb Biotechnol 26:1419-1426

Kılıç NK (2009) Enhancement of phenol biodegradation by Ochrobactrum sp. isolated from industrial wastewaters. Int Biodeterior Biodegrad 63:778-781

Koma D, Sakashita Y, Kubota K, Fujii Y, Hasumi F, Chung SY, Kubo M (2003) Degradation of car engine base oil by Rhodococcus sp. NDKK48 and Gordonia sp. NDKY76A. Biosci Biotechnol Biochem 67:1590-1593

Lee SH, Oh BI, Kim J (2008) Effect of various amendments on heavy mineral oil bioremediation and soil microbial activity. Bioresour Technol 99:2578-2587

Lin CW, Chen LH, Yet-Pole I, Lai CY (2010) Microbial communities and biodegradation in lab-scale BTEX-contaminated groundwater remediation using an oxygen-releasing reactive barrier. Bioprocess Biosyst Eng 33:383-391

Lunkenheimer K, Wantke KD (1981) Determination of surface tension of surfactant solutions applying the method of Lecomte du Nouy (ring tensiometer). Colloid Polym Sci 259:354-366

Mehdi H, Giti E (2008) Investigation of alkane biodegradation using the microtiter plate method and correlation between biofilm formation, biosurfactant production and crude oil biodegradation. Int Biodeterior Biodegrad 62:170-178

Misra V, Pandey SD (2005) Hazardous waste, impact on health and environment for development of better waste management strategies in future in India. Environ Int 31:417-431

Molnar M, Leitgib L, Gruiz K, Fenyvesi E, Szaniszlo N, Szejtli J, Fava F (2005) Enhanced biodegradation of transformer oil in soils with cyclodextrin-from the laboratory to the field. Biodegradation 16:159-168

Montagnolli RN, Lopes PRM, Bidoia ED (2009) Applied models to biodegradation kinetics of lubricant and vegetable oils in wastewater. Int Biodeterior Biodegrad 63:297-305

Myers RH, Montgomery DC (2002) Response surface methodology: process and product in optimization using designed experiments, 4th edn. Wiley, New York

Obayori OS, Ilori MO, Adebusoye SA, Oyetibo GO, Amund OO (2009) Degradation of hydrocarbons and biosurfactant production by Pseudomonas sp strain LP1. World J Microbiol Biotechnol 25:1615-1623

Qiu X, Zhong Q, Li M, Bai W, Li B (2007) Biodegradation of pnitrophenol by methyl parathion-degrading Ochrobactrum sp. B2. Int Biodeterior Biodegrad 59:297-301

Rauckyte T, Hargreaves DJ, Pawlak Z (2006) Determination of heavy metals and volatile aromatic compounds in used engine oils and sludges. Fuel 85:481-485

Ray S, Khillare PS, Agarwal T, Shridhar V (2008) Assessment of PAHs in soil around the International Airport in Delhi, India. J Hazard Mater 156:9-16

Ron EZ, Rosenberg E (2014) Enhanced bioremediation of oil spills in the sea. Curr Opin Biotechnol 27:191-194

Sikkema J, de Bont JA, Poolman B (1995) Mechanisms of membrane toxicity of hydrocarbons. Microbiol Mol Biol Rev 59:201-222

Singh A, Kuhad R, Ward O (2009) Advances in applied bioremediation. Springer Verlag, Berlin

US EPA (2004) Cleaning up the nation's waste sites: markets and technology trends. Technology Innovation and Field Services Division, Office of Solid Waste and Emergency Response, EPA 542-R-04-015. US Environmental Protection Agency, Washington, DC

Wang H, Xu R, Li F, Qiao J, Zhang B (2010) Efficient degradation of lube oil by a mixed bacterial consortium. J Environ Sci 22:381-388

Wang XB, Chi CQ, Nie Y, Tang YQ, Tan Y, Wu G, Wu XL (2011) Degradation of petroleum hydrocarbons (C6-C40) and crude oil by a novel Dietzia strain. Bioresour Technol 102:7755-7761

Yuan YJ, Lu ZX, Huang LJ, Bie XM, Lü FX, Li Y (2006) Optimization of a medium for enhancing nicotine biodegradation by Ochrobactrum intermedium DN2. J Appl Microbiol 101:691-697

Zhang Z, Hou Z, Yang C, Ma C, Tao F, Xu P (2011) Degradation of $n$-alkanes and polycyclic aromatic hydrocarbons in petroleum by a newly isolated Pseudomonas aeruginosa DQ8. Bioresour Technol 102:4111-4116 